\title{
Consequences of phosphoenolpyruvate:sugar phosphotranferase system and pyruvate kinase isozymes inactivation in central carbon metabolism flux distribution in Escherichia coli
}

\author{
Eugenio Meza ${ }^{1 \dagger}$, Judith Becker ${ }^{2+}$, Francisco Bolivar ${ }^{1}$, Guillermo Gosset ${ }^{1}$ and Christoph Wittmann ${ }^{2 *}$
}

\begin{abstract}
Background: In Escherichia coli phosphoenolpyruvate (PEP) is a key central metabolism intermediate that participates in glucose transport, as precursor in several biosynthetic pathways and it is involved in allosteric regulation of glycolytic enzymes. In this work we generated W3110 derivative strains that lack the main PEP consumers PEP:sugar phosphotransferase system (PTS') and pyruvate kinase isozymes PykA and PykF (PTS pykA' and PTS pykF ${ }^{-}$). To characterize the effects of these modifications on cell physiology, carbon flux distribution and aromatics production capacity were determined.

Results: When compared to reference strain W3110, strain VH33 (PTS) displayed lower specific rates for growth, glucose consumption and acetate production as well as a higher biomass yield from glucose. These phenotypic effects were even more pronounced by the additional inactivation of PykA or PykF. Carbon flux analysis revealed that PTS inactivation causes a redirection of metabolic flux towards biomass formation. A cycle involving PEP carboxylase (Ppc) and PEP carboxykinase (Pck) was detected in all strains. In strains W3110, VH33 (PTS') and VH35 (PTS', pykF), the net flux in this cycle was inversely correlated with the specific rate of glucose consumption and inactivation of Pck in these strains caused a reduction in growth rate. In the PTS background, inactivation of PykA caused a reduction in Ppc and Pck cycling as well as a reduction in flux to TCA, whereas inactivation of PykF caused an increase in anaplerotic flux from PEP to OAA and an increased flux to TCA. The wild-type and mutant strains were modified to overproduce L-phenylalanine. In resting cells experiments, compared to reference strain, a 10, 4 and 7-fold higher aromatics yields from glucose were observed as consequence of PTS, PTS PykA and PTS PykF inactivation.
\end{abstract}

Conclusions: Metabolic flux analysis performed on strains lacking the main activities generating pyruvate from PEP revealed the high degree of flexibility to perturbations of the central metabolic network in E. coli. The observed responses to reduced glucose uptake and PEP to pyruvate rate of conversion caused by PTS, PykA and PykF inactivation included flux rerouting in several central metabolism nodes towards anabolic biosynthetic reactions, thus compensating for carbon limitation in these mutant strains. The detected cycle involving Ppc and Pck was found to be required for maintaining the specific growth and glucose consumption rates in all studied strains. Strains VH33 (PTS-), VH34 (PTS pykA-) and VH35 (PTS- pykF) have useful properties for biotechnological processes, such as increased PEP availability and high biomass yields from glucose, making them useful for the production of aromatic compounds or recombinant proteins.

Keywords: PTS, Pyruvate kinase, Aromatic amino acids

\footnotetext{
* Correspondence: c.wittmann@tu-braunschweig.de

${ }^{\dagger}$ Equal contributors

${ }^{2}$ Institute of Biochemical Engineering, Technische Universität Braunschweig,

Gaußstr. 17, D-38106, Braunschweig, Germany

Full list of author information is available at the end of the article
} 


\section{Background}

Escherichia coli is a fast growing microorganism that can be modified by a wide variety of molecular tools, thus enabling the generation of industrial strains for the production of metabolites and recombinant proteins. This bacterium can grow in defined media using glucose as sole carbon source, and under this condition, central metabolism is mainly constituted by the EmbdenMeyerhof-Parnas (EMP) pathway, the pentose phosphate pathway (PPP) and the tricarboxylic acid (TCA) cycle. Together, these three pathways provide energy (ATP, GTP), reducing power (NADH, NADPH, $\mathrm{FADH}_{2}$ ) and biomass precursors for the cell [1]. When E. coli grows on glucose as carbon source, this sugar is imported by the phosphoenolpyruvate (PEP):sugar phosphotransferase system (PTS) that couples the transfer of the phosphate group from PEP to this sugar, thus generating as products glucose 6-phosphate (G6P) and pyruvate (PYR) [2-4] (Figure 1). In E. coli, PEP also participates as substrate in the reaction catalyzed by the pyruvate kinase (Pyk) isozymes (PykA and PykF), yielding PYR and ATP [5]. Furthermore, PEP connects the EMP pathway and the TCA cycle via an anaplerotic reaction catalyzed by PEP carboxylase (Ppc) that generates oxaloacetate (OAA) [6,7]. During gluconeogenic metabolism PEP synthase (Pps) converts PYR to PEP and PEP carboxykinase (Pck) forms PEP from OAA [7,8]. In addition to its participation in metabolic reactions, PEP also plays a regulatory role. An inhibitory effect of PEP has been described on the EMP pathway enzymes glucokinase (Glk), phosphoglucoisomerase (Pgi), phosphofructokinase (Pfk) and aldolase (FbaA) [9] whereas an activation effect has been described in the enzymes phosphate acetyltransferase (Pta) and acetate kinase (Aks) [10] (Figure 1).

The first step in the common aromatic pathway or shikimate (SHIK) pathway consists in the condensation of PEP and erythrose 4 phosphate (E4P) to yield 3-deoxyD-arabinoheptulosonate 7 phosphate (DAHP). In E. coli, this reaction is catalyzed by the DAHP synthase isozymes (AroF, AroG and AroH) [11] (Figures 1 and 2b). Within this pathway, the synthesis of dehydroshikimate (DHS) to yield SHIK, a reaction catalyzed by the enzyme SHIK dehydrogenase (AroE), is a step that requires reducing power in the form of NADPH. An additional PEP molecule is required to condense with SHIK-3-phosphate (S3P) to yield 5-enol-pyruvylshikimate-3-phosphate (EPSP) by the enzyme EPSP synthase (AroA) [12]. The final product of the SHIK pathway is chorismate $(\mathrm{CHO})$, a precursor molecule for the synthesis of the aromatic amino acids tryptophan (TRP), tyrosine (TYR) and phenylalanine (PHE) [13] (Figure $2 \mathrm{~b}$ ). The PHE biosynthetic pathway starts with the conversion of $\mathrm{CHO}$ to prephenate and subsequently to phenylpyruvate (PPY) by the bifunctional enzyme $\mathrm{CHO}$ mutase-prephenate dehydratase (CM-PDT), encoded by gene pheA. In the last step of this pathway, the enzyme PHE aminotransferase (TyrB) transfers an amino group from glutamate to PPY to yield PHE (Figure 2b).

The aromatic amino acids and some intermediates of the SHIK pathway are metabolites having industrial applications [14-19]. These include the aromatic amino acid PHE as precursor of the low-calorie sweetener aspartame, L-3,4-dihydroxyphenylalanine (L-DOPA) used for treatment of Parkinson's disease [20] and the intermediate SHIK as precursor of the antiviral osetalmivir $[21,22]$. Several reports indicate that PEP availability is one of the main factors to be considered when designing a strategy to generate aromatics production strains $[19,23,24]$. In this regard, PTS, PykA and PykF, as the main PEP consuming reactions in E. coli, have been the subject of several studies to understand their role on the cell's physiology [25-29]. In E. coli, PTS is the main PEPconsuming activity during growth on glucose [2-4]. For this reason, PTS can be considered the most promising cellular target to inactivate in order to increase PEP availability and therefore, aromatics yield from glucose [15]. A mutant strain lacking PTS activity (PTS ${ }^{-}$) displays poor growth on glucose (PTS ${ }^{-}$glc phenotype) which is clearly an undesirable trait in the context of an industrial production process. To improve the characteristics of a PTS $^{-}$glc $^{-}$strain, a chemostat selection method was employed, thereby it was possible to isolate mutants that display rapid growth on glucose ( $\mathrm{PTS}^{-}$glc $^{+}$phenotype) [30]. Characterization of one of such mutants revealed that glucose import and phosphorylation are dependent on the GalP symporter and glucokinase (Glk), respectively [27,31] (Figure 1). This mutant was modified for aromatics production and it was determined that it can produce PHE with a higher yield from glucose when compared to an isogenic $\mathrm{PTS}^{+}$strain $[23,30,32]$.

In E. coli the total Pyk activity is dependent on the PykA and PykF isozymes which constitute the second main PEPconsuming activity in the cell [5,33-35]. These isozymes are encoded by genes $p y k A$ and $p y k F$, whereby $p y k F$ is regulated by the catabolite repressor/activator protein (Cra) [36,37]. It has recently been demonstrated that $p y k A$ might also be regulated by Cra [38]. Both Pyk isozymes are subject to metabolic control of enzyme activity. The enzyme PykF is activated by fructose-1, 6-bisphosphate (FBP), whereas ATP, GTP and succinyl coenzyme A (SUCC CoA) are negative effectors [36,39-44]. The enzyme PykA is activated by adenosine monophosphate (AMP) and sugars from the PPP (gluconate 6-phosphate, ribose 5-phosphate, ribulose 5-phosphate, heptulosonate 7-phosphate and xylulose 5-phosphate) whereas SUCC CoA is a negative effector $[45,46]$. It has been observed in E. coli that PykF displays the highest enzyme activity when compared to PykA in wild type as well as the PTS ${ }^{-}$background during growth on 


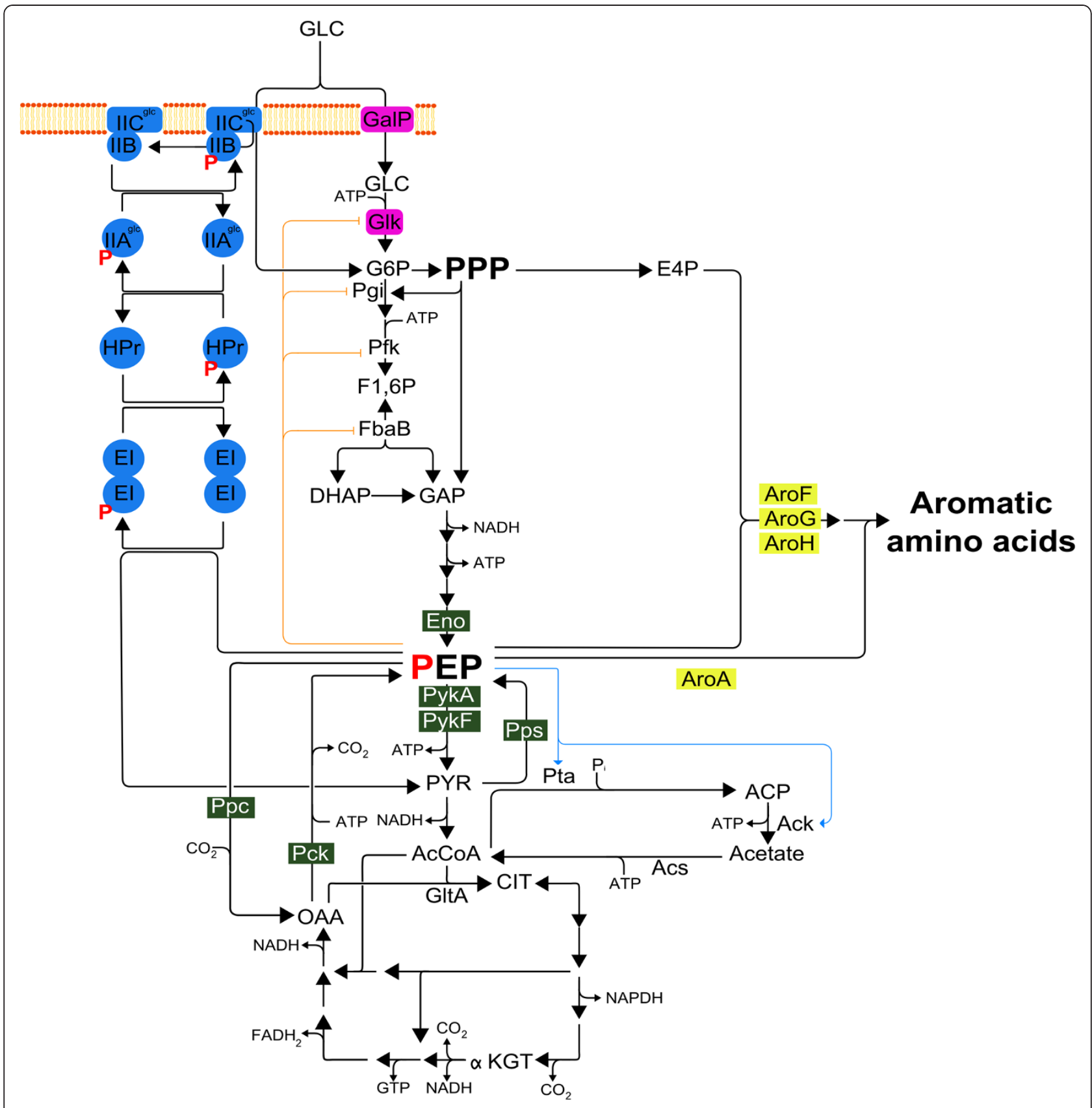

Figure 1 Central carbon metabolism pathways in E. coli. The Embden-Meyerhof-Parnas (EMP), pentose phosphate pathway (PPP) and tricarboxylic acid cycle (TCA) in E. coli during growth in glucose. In the figure PTS (in blue), the non PTS glucose uptake system (in purple), PEP node (green) and AAA (yellow) enzymes are depicted. The allosteric effects that PEP has in EMP and acetate biosynthesis are in orange line for inhibition and blue arrow for activation.

glucose as sole carbon source [28]. Based on these data, PykF is considered the main Pyk activity in E. coli [25,26,29].

Both PykA and PykF are well characterized proteins, however, their specific roles in central carbon metabolism are still not completely clear. Carbon flux studies in Pyk deficient $E$. coli strains have been performed in a genetic background where PTS is active, therefore, PTS-dependent synthesis of PYR from PEP is still occurring by this activity in the mutant strains $[25,26,29]$. An E. coli strain lacking PTS activity provides a background where the PEP to PYR reaction is dependent only on Pyk activity, thus enabling a study designed to provide further insight into the roles of PTS, PykA and PykF on central metabolism. The use of several "omics" tools to unravel $E$. coli's cellular responses 


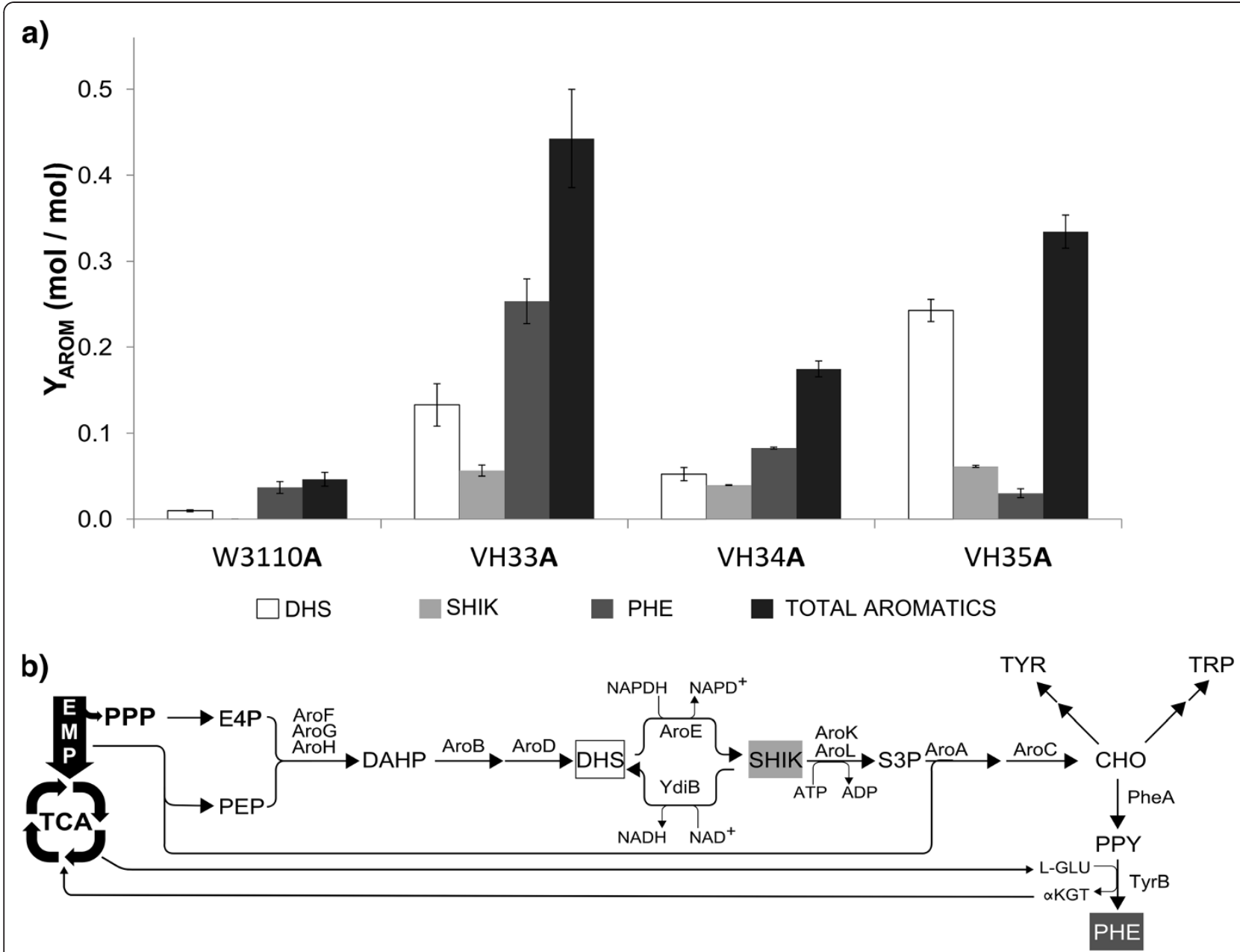

Figure 2 Aromatic amino acids biosynthesis. a) DHS, SHIK, PHE and (DHS + SHIK + PHE) yields from glucose. The values shown are the result of three independent experiments. b) The common aromatic pathway and the final pathways leading to PHE, TYR and TRP.

has allowed a better understanding of the physiology of this important industrial microorganism [25,26,29]. In this work we used a fluxome [47] approach to describe the phenotypic response (carbon fluxes) to the absence of PTS and also to a condition when the PYR to PEP reaction is dependent only on PykA or PykF activity.

\section{Methods}

\section{Strains and plasmids}

The strains used in this work are described in Table 1. The reference strain E. coli W3110 is an $\mathrm{F}^{-} \lambda^{-}$galactose fermenting derivative of E. coli K-12 [48]. Strain VH32 is a $\Delta p t s I$, ptsH, crr::kan $\Delta$ lacI, lacZ::loxP (PTS ${ }^{-}$) derivative of W3110 displaying a PTS $^{-}$glc phenotype [49]. Strain $\mathrm{VH} 32$ galP $^{+}$is a derivative of VH32 that was constructed by replacing the native galactose permease gene ( galP) promoter by the trc promoter [50]. The method employed for this purpose leaves a stable chloramphenicol $(\mathrm{Cm})$ resistance cassette (cat) flanked by phage $\lambda$ Red recombinase
(FLP) recognition target (FRT) sites [51]. In this strain, glucose import is dependent on GalP and glucose phosphorylation on glucokinase (Glk) activity encoded by the chromosomal glk gene. Since the lacI gene was deleted in strain $\mathrm{VH} 32$ galP $^{+}$, expression of galP from the trc promoter is constitutive. To generate strain VH33, the cat resistance cassette was removed from $\mathrm{VH} 32$ galP $^{+}$by transforming it with plasmid pCP20 that expresses FLP [52]. Strains VH34 ( $\Delta p t s I, p t s H, c r r: k a n, p y k A:: c a t)$ and VH35 ( $\Delta$ ptsI, ptsH, crr::kan, pykF::aacC1) were generated by $\mathrm{P} 1$ transduction of VH33 using PB28 strain ( $\Delta p t s I$, ptsH, crr::kan, pykA::cat, pykF::aacC1) [28] lysate as a donor and selecting with the corresponding antibiotic: chloramphenicol $(\mathrm{Cm})$ or gentamicin (Gen). Verification of the desired genotype was made by PCR; in the case of pykA interruption by cat the 5' primer was TGA AGG AAT CGC GTT TTG ATA and the 3' primer: GTA TTA GTA GAA CCC ACG GTA. For verification of $p y k F$ interruption with aacC1 the PCR reaction included the 5 
Table 1 Escherichia coli strains and plasmids used

\begin{tabular}{|c|c|c|}
\hline Strain & Description & Reference \\
\hline PB28 & $\Delta p t s l$, ptsH, crr:kan, pykA::cat, pykF::gen & [28] \\
\hline JM101 pck & SupE, thi, $\Delta$ (lac-proAB), F', pck::cat & [53] \\
\hline W3110 & $\mathrm{F}^{-} \lambda^{-} \mid \mathrm{NV}(r r n \mathrm{D}-r r n \mathrm{E}) 1$ & [48] \\
\hline VH32 galP ${ }^{+}$ & $\begin{array}{c}\text { W31 } 10 \Delta \text { ptsH, ptsl, crr::Km, } \Delta \text { lacl, } \\
\text { lacZ::IoxP } \Delta \mathrm{P}_{\text {galp: }:: \text { cat, } \mathrm{P}_{T r c}}\end{array}$ & [50] \\
\hline VH33 & VH32 galP ${ }^{+} \Delta \mathrm{P}_{\text {galp:: }} \mathrm{P}_{T r c}$ & This work \\
\hline VH34 & VH33 pykA::cat & This work \\
\hline VH35 & VH33 pykF::gen & This work \\
\hline W3110 pck & W3110 pck::cat & This work \\
\hline VH33 pck & VH33 pck::cat & This work \\
\hline VH34 pck & VH34 pck::cat & This work \\
\hline VH35 pck & VH35 pck::cat & This work \\
\hline W3110A & W3110/JLBaroG fbr tktA, pTrcpheA ev2 & This work \\
\hline VH33A & VH33/JLBaroG fbr tktA, pTrcpheA ${ }^{\text {ev2 }}$ & This work \\
\hline VH34A & VH34/JLBaroG Gbr tktA, pTrcpheA $A^{e v 2}$ & This work \\
\hline VH35A & VH35/JLBaroG fbr tktA, pTrcpheA ev2 & This work \\
\hline \multicolumn{3}{|l|}{ Plasmids } \\
\hline pCP20 & $\mathrm{FLP}^{+}, \lambda c i 857^{+}, \lambda \mathrm{p}_{\mathrm{R}} \mathrm{Rep}^{\mathrm{ts}}, \mathrm{Ap}^{\mathrm{R}}, \mathrm{Cm}^{\mathrm{R}}$ & [52] \\
\hline pJLBaroG ${ }^{\text {fbr }} t k t A$ & $\begin{array}{l}\text { aroG } G^{\mathrm{fbr}} \text { under control of the lacUV5 } \\
\text { promoter; and tktA under its native } \\
\text { promoter, carries lacla and tet genes. } \\
\text { Replication origin from pACYC184 }\end{array}$ & [55] \\
\hline pTrcpheA ev2 & $\begin{array}{l}\text { Evolved pheA } A^{\mathrm{ev} 2} \text { under the control of } \\
\text { lacUV5 promoter. Ev2 superscript means } \\
\text { 2nd version of evolved } p h e A^{\mathrm{fbr}} \text { gene. }\end{array}$ & {$[32]$} \\
\hline
\end{tabular}

primer: CGT AAC CTT TTC CCT GGA ACG and the 3' primer: GAG TCC GGC TGA TGT TGG GAG TAG GTG GCT. pck derivatives were generated by P1 transduction in W3110, VH33, and VH35 using a JM101 pck strain [53] (supE, thi, $\Delta$ (lac-proAB), F, pck::cat) lysate as donor and selecting with $\mathrm{Cm}$. In these $p c k$ strains the $c a t$ cassette is flanked by FRT sites, so in order to generate strain VH34 pck, the cat resistance cassette was removed from VH33 pck strain by transforming it with plasmid pCP20, and then performing P1 transduction in the resulting strain using a lysate from PB28 ( $\Delta p t s I, p t s H$, crr::kan, pykA::cat, pykF::gen) as a donor. Resulting strain VH33 pck pykA- (VH34 pck') strain was selected using medium with $\mathrm{Cm}$. Verification of the pck::cat mutation in derivative strains was done by PCR using primers reported elsewere [54] (data not shown). Two plasmids were used in this work (Table 1). pJLBaroG ${ }^{\mathrm{fbr}} t k t A$ [55] is a pACYC184 derivative that harbors gene aro $G^{\mathrm{fbr}}$ encoding a feedback resistance version of DAHP synthase. This plasmid also contains a copy of the gene $t k t \mathrm{~A}$ that encodes transketolase, an enzyme that catalyzes the reversible conversion of D-fructose-6-phosphate (F6P) and D-glyceraldehyde-5phosphate (G5P) into D-xylulose-5-phosphate (XU5P) and E4P. The aro $^{\mathrm{fbr}}$ gene is under transcriptional control of the lacUV5 strong promoter that is inducible by isopropyl- $\beta$-D-thiogalactopyranoside (IPTG), whereas the $t k t$ A gene is under control of its native promoter. Plasmid $\mathrm{p}$ TrcpheA ${ }^{\mathrm{ev} 2}$ contains a second evolved version of a mutant version of chorismate mutase-prephenate dehydratase enzyme (PheA) [32]. This gene is under transcriptional control of the the trc promoter. Strains W3110, VH33, VH34 and VH35 were sequentially transformed with plasmids pJLBaroG ${ }^{\mathrm{fbr}} t k t A$ and $\mathrm{p}$ Trcphe $A^{\mathrm{ev} 2}$ to generate strains W3110A, VH33A, VH34A and VH35A, respectively.

\section{Growth media and cultivation conditions}

The medium used during mutant strains construction and selection was Luria-Bertani (LB) with the corresponding antibiotic: $\mathrm{Cm} 10 \mu \mathrm{g} / \mathrm{ml}, \mathrm{Km} 10 \mu \mathrm{g} / \mathrm{ml}$ and $\mathrm{Gm} 5 \mu \mathrm{g} / \mathrm{ml}$ (Table 1). In shake flask cultures and labeling experiment, minimal medium was used. It contained glucose as the sole carbon source at a concentration of $10 \mathrm{~g} / \mathrm{l}, \mathrm{K}_{2} \mathrm{HPO}_{4}$ $90 \mathrm{mM}, \quad \mathrm{KH}_{2} \mathrm{PO}_{4} \quad 10 \mathrm{mM}, \quad\left(\mathrm{NH}_{4}\right)_{2} \mathrm{SO}_{4} 40 \mathrm{mM}$, $\mathrm{NaCl} 20 \mathrm{mM}, \mathrm{MgSO}_{4} \cdot 2 \mathrm{H}_{2} \mathrm{O} 1.6 \mathrm{mM}, \mathrm{CaCl}_{2} 0.05 \mathrm{mM}$, $\mathrm{FeSO}_{4} \cdot 7 \mathrm{H}_{2} \mathrm{O} 0.072 \mathrm{mM}$ and vitamin $\mathrm{B} 10.05 \mathrm{mM}$. Glucose and salts solution were sterilized separately at $121^{\circ} \mathrm{C}$ during 20 minutes and vitamin B1 was sterilized by filtration. All stock cultures were stored at $-70^{\circ} \mathrm{C}$ in $\mathrm{LB}$ medium containing glycerol $(25 \% \mathrm{v} / \mathrm{v})$. For fermentation profiles, $5 \mathrm{ml}$ of LB overnight cultures were used as inoculum, washed twice with minimal medium and then subcultured in shake flask containing $30 \mathrm{ml}$ of minimal medium with $5 \mathrm{~g} / \mathrm{l}$ glucose starting with an $\mathrm{OD}_{600 \mathrm{~nm}}=0.1$ and incubated at $37^{\circ} \mathrm{C}, 300 \mathrm{rpm}$ during 12 hours in an orbital shaker (G25, New Brunswick Scientific, Inc., New Brunswick, NJ). These cultures were used to inoculate $30 \mathrm{ml}$ of minimal medium with $10 \mathrm{~g} / \mathrm{l}$ glucose at an $\mathrm{OD}_{600 \mathrm{~nm}}=0.01$ and then incubated at $37^{\circ} \mathrm{C}, 300 \mathrm{rpm}$ during 24 hours. Every 2 hours $1 \mathrm{ml}$ of culture was harvested, OD was determined (Biomate 5, ThermoSpectronic), cells were centrifuged $(10,000 \mathrm{~g}$ for $10 \mathrm{~min})$ and the supernatant used for metabolite determination by HPLC. For labeling experiments, the naturally labeled glucose was substituted by $99 \%$ [1- ${ }^{13} \mathrm{C}$ ] labeled glucose (Cambridge Isotope Laboratories, Andover, USA). Cells were harvested during the exponential growth phase at 9 hours $\left(\mathrm{OD}_{600 \mathrm{~nm}}=3.72\right)$ for W3110, 15 hours $\left(\mathrm{OD}_{600 \mathrm{~nm}}=6.68\right)$ for VH33, 16 hours for VH34 $\left(\mathrm{OD}_{600 \mathrm{~nm}}=7.68\right)$ and 16 hours for VH35 $\left(\mathrm{OD}_{600 \mathrm{~nm}}=5.1\right)$. Cultures for determining the correlation between optical density $(600 \mathrm{~nm})$ and cell dry mass (CDM) were started with $5 \mathrm{ml}$ of LB overnight cultures that were used as inoculum, washed twice with minimal medium and then used to inoculate a shake flask containing $50 \mathrm{ml}$ of minimal medium with glucose $5 \mathrm{~g} / \mathrm{l}$ starting at an $\mathrm{OD}_{600 \mathrm{~nm}}=0.1$ and incubated at $37^{\circ} \mathrm{C}$, $300 \mathrm{rpm}$ for 12 hours in an orbital shaker. To determine the correlation between optical density and CDM, $10 \mathrm{ml}$ of cells grown in minimal medium were harvested and 
filtered at different optical densities, washed twice with water and dried at $80^{\circ} \mathrm{C}$ until constant weight. The correlation between $\mathrm{OD}_{600 \mathrm{~nm}}$ and $\mathrm{CDM}[\mathrm{g} / \mathrm{L}]$ was determined as $C D M=0.45 \times \mathrm{OD}_{600 \mathrm{~nm}}$.

\section{Sample preparation for labeling analysis and estimation of metabolic flux}

The total volume of cultures grown with $\left[1-{ }^{13} \mathrm{C}\right]$ labeled glucose $(10 \mathrm{ml})$ was centrifuged and the pellet (about $1 \mathrm{mg}$ dry cell mass) was washed twice with cold water $\left(4^{\circ} \mathrm{C}\right)$. Hydrolysis was performed with $50 \mu \mathrm{L}$ of $\mathrm{HCl} 6 \mathrm{~N}$ at $110^{\circ} \mathrm{C}$ for 24 hours. The insoluble debris was separated by filtration (Titan 2 HPLC filter purple, $0.2 \mu$ m nylon membrane, Sun-Sri), neutralized with $\mathrm{NaOH} 6 \mathrm{~N}$ and lyophilized. Derivatization with (trimethylsilyl) trifluoroacetamide (BSTFA) of the lyophilized cell protein was performed to determine ${ }^{13} \mathrm{C}$ labeling pattern of proteinogenic amino acids by GC-MS as previously described [56]. The metabolic network for simulation was comprised of the EMP pathway, the PPP, the TCA cycle and the Ender Duodoroff pathway. Glyoxylate shunt, anaplerotic reactions and malic enzyme were included. The simulation was done as previously described [56].

\section{Resting cells experiments}

To determine PHE production and yield in W3110A, VH33A, VH34A and VH35A strains, a resting cells method was used. $5 \mathrm{ml}$ of LB overnight cultures were used as inoculum, washed twice with minimal medium supplemented with $10 \mathrm{~g} / \mathrm{l}$ of yeast extract $(\mathrm{MM}+\mathrm{YE})$ and then subcultured in shake flask containing $50 \mathrm{ml}$ of $\mathrm{MM}+\mathrm{YE}$ with $5 \mathrm{~g} / \mathrm{l}$ glucose starting with an $\mathrm{OD}_{600 \mathrm{~nm}}=0.1$ and incubated at $37^{\circ} \mathrm{C}, 300 \mathrm{rpm}$ until optic density of 2.0. At this point, cells were harvested, washed twice with minimal medium and suspended in $50 \mathrm{ml}$ of minimal medium with $10 \mathrm{~g} / \mathrm{l}$ glucose. To arrest cellular growth $50 \mu \mathrm{g} / \mathrm{ml}$ of chloramphenicol was added as well as $100 \mu \mathrm{M}$ IPTG for aroG ${ }^{\mathrm{fbr}}$ and phe $\mathrm{A}^{\mathrm{ev} 2}$ transcriptional induction. Cell cultures were incubated during 12 hours in an orbital shaker. Every hour, $1 \mathrm{ml}$ of culture was harvested, $\mathrm{OD}_{600 \mathrm{~nm}}$ was determined, cells were centrifuged (10,000 g for $10 \mathrm{~min})$ and the supernatant used for metabolite determination by HPLC.

\section{Determination of glucose, organic acids, DHS, SHIK and PHE}

For determination concentrations of D-glucose and organic acids, an Aminex HPX-87 $\mathrm{H}$ column (300 X $7.8 \mathrm{~mm}$; 9 Am Bio-Rad, Hercules, CA) was used. Separation was carried out isocratically with $5 \mathrm{mM} \mathrm{H}_{2} \mathrm{SO}_{4}$ at a flow rate of $0.5 \mathrm{ml} / \mathrm{min}$ and a temperature of $50^{\circ} \mathrm{C}$. Under these conditions glucose was detected by refraction index and acetic acid, DHS and SHIK by photodiode array at $210 \mathrm{~nm}$. For these measurements a Waters HPLC system was used: 600E quaternary pump, 717 automatic injector, 2410 refraction index, and 996 photodiode array.

PHE concentration in culture supernatants was quantified with a Phenomenex Synergy Hydro RP18 column (150 by $4.6 \mathrm{~mm} ; 4 \mathrm{~m}$ ) attached to an Agilent 1100 HPLC system (Agilent Technologies, Palo Alto, CA). Running conditions were: mobile phase, $0.2 \%$ TFA in $40 \%$ methanol; flow, $0.5 \mathrm{ml} / \mathrm{min}$. Detection was performed with a photodiode array at $280 \mathrm{~nm}$.

\section{Determination of Pyk enzyme activity}

Cells in exponential growth phase were harvested by centrifugation $(10,000 \mathrm{~g}$ for $10 \mathrm{~min})$, washed twice with $50 \mathrm{mM}$ sodium phosphate buffer $\left(\mathrm{pH} 7.2\right.$ at $\left.4^{\circ} \mathrm{C}\right)$, suspended in the same buffer, and disrupted by sonication using four 15-second, $\lambda=10 \mu \mathrm{m}$, pulses in a cold bath (Ultrasonic Disrupter, Soniprep 150). The cell debris was removed by centrifugation $\left(10,000 \mathrm{~g}, 10 \mathrm{~min}, 4^{\circ} \mathrm{C}\right)$, and the resulting crude cell extracts were immediately used to determine enzyme activities. Pyk enzyme activities were determined spectrophotometrically (Biomate 5, ThermoSpectronic) using $1 \mathrm{U}$ of lactate dehydrogenase (LDH) as coupling enzyme [57]. The reaction mix contained $\mathrm{KCl}$ $50 \mathrm{mM}, \mathrm{MgCl}_{2} 5 \mathrm{mM}$, ADP $2 \mathrm{mM}$, NADH $0.2 \mathrm{mM}$, PEP $100 \mathrm{mM}$, fructose-1,6 biphosphate (FBP) $1 \mathrm{mM}$, AMP $1 \mathrm{mM}$ and ribose-5-phosphate (R5P) $1 \mathrm{mM}$. One unit of specific enzyme activity was defined as the amount of enzyme required to convert $1 \mu \mathrm{mol}$ of substrate into the specific product per minute per milligram of protein at $30^{\circ} \mathrm{C}$. Protein concentrations were measured using the Lowry method. Enzyme activities reported are the average of three independent experiments.

\section{Results}

\section{Pyk mutant strains verification}

Strain VH33 is a W3110 mutant derivative lacking PTS activity as a result of deleting genes ptsI, ptsH and crr. This strain was also modified in order to increase its glucose import capacity by replacing the native promoter of gene galP by the strong trc promoter and inactivating the lacI gene. As a result of these modifications VH33 displays a constitutive PTS $^{-}$glc $^{+}$phenotype. In this work, strain VH33 was further modified by inactivating either $p y k A$ or $p y k F$, to generate strains $\mathrm{VH} 34$ and $\mathrm{VH} 35$, respectively.

Figure $3 a$ depicts the genomic regions of $p y k A$ and $p y k F$ and the resulting modifications after interruption with cat (VH34) or aacC1 (VH35) antibiotic resistance genes. The forward primer for verification of $p y k A$ interruption anneals outside of the $p y k A$ region while the reverse primer binds at the end of the gene. PCR amplification using genomic DNA from VH33, VH34 and VH35 as template showed two expected bands: one of $1.6 \mathrm{~kb}$ for VH33 and VH35 and one of $2.3 \mathrm{~kb}$ for $\mathrm{VH} 34$ due to the insertion of the cat gene in the pykA gene (Figure $3 \mathrm{~b}$ ). For verifying strain VH35, the 


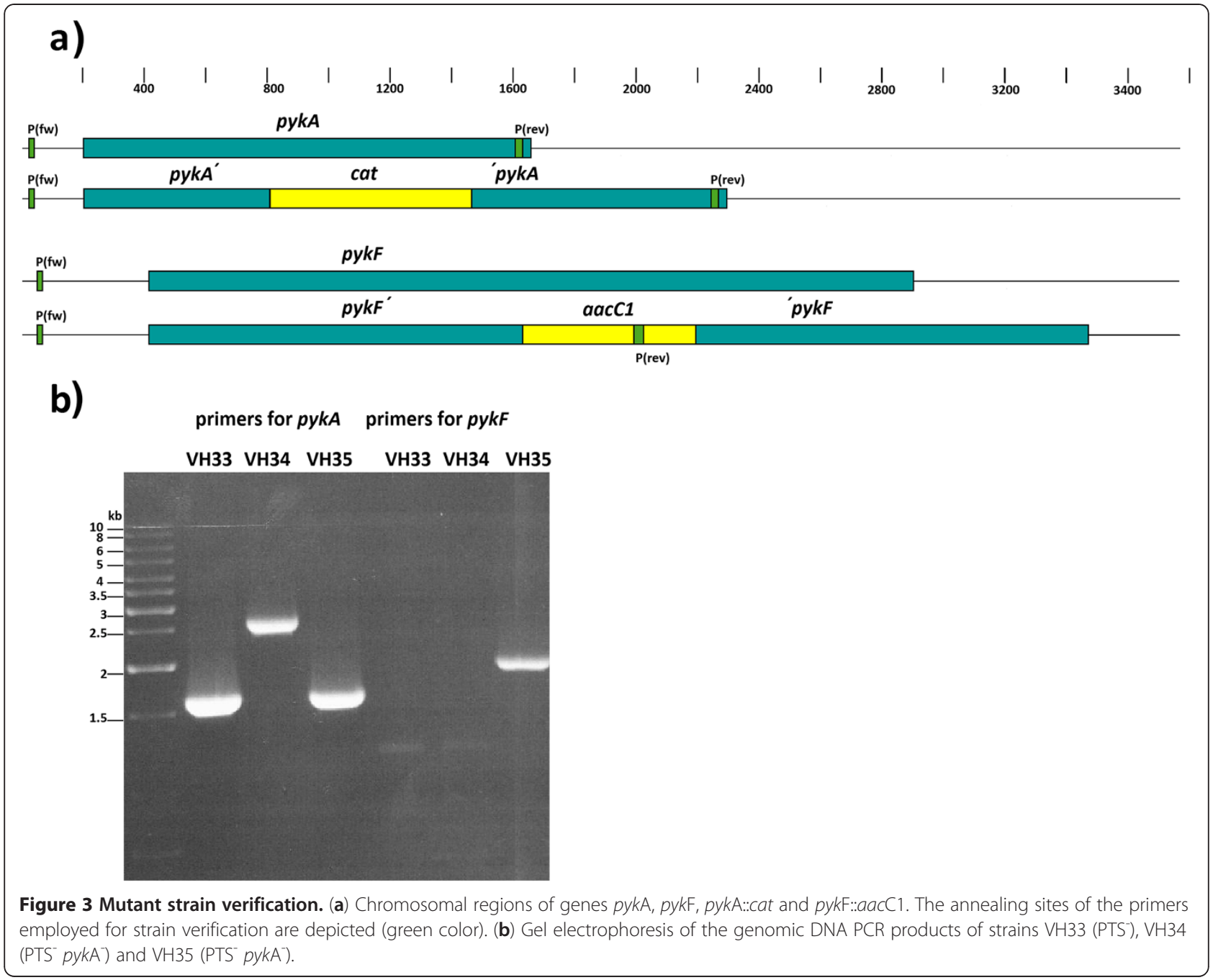

forward primer employed anneals outside of the $p y k F$ coding region while the reverse primer binds to the aacC1 gene. When using genomic DNA from VH33, VH34 and VH35 as template, no PCR product was observed for VH33 or VH34 while the expected $2 \mathrm{~kb}$ band was observed for VH35 (Figure 3b). These results, together with the expected antibiotic resistance phenoptypes, indicated that interruptions of $p y k A$ by $c a t$ and $p y k F$ by $a a c C 1$ were present in VH34 and VH35.

\section{Measurement of Pyk enzyme activity}

In the wild type strain W3110 the activities that determine the PEP $\rightarrow$ PYR flux are PTS, PykA and PykF, while in strain VH33 this reaction is catalyzed only by both Pyk isozymes. In strains VH34 and VH35, the PEP $\rightarrow$ PYR reaction is dependent only on PykF or PykA, respectively. The measured total Pyk enzyme activity (PykA + PykF) in strain W3110 was $0.18 \pm 0.03 \mathrm{U} / \mathrm{mg}$ and a similar value was observed in strain VH33 (Figure 4). In strain VH34, where only the PykF isozyme is active, the Pyk specific activity was $0.21 \pm 0.01 \mathrm{U} / \mathrm{mg}$, whereas in the VH35 strain the Pyk activity, dependent only on PykA, was $0.05 \pm 0.01 \mathrm{U} / \mathrm{mg}$ (Figure 4).

\section{Batch culture profiles}

To determine the effects on kinetic and stoichiometric parameters caused by PTS, PTS $p y k A$ and PTS $p y k F$ inactivations, batch cultures in minimal medium with $10 \mathrm{~g} / \mathrm{l}$ of glucose as sole carbon source were performed (Table 2). Under these conditions, reference strain W3110 displayed a $\mu$ of $0.69 \mathrm{~h}^{-1}$ and a $\mathrm{q}_{\mathrm{Glc}}$ of $16.1 \mathrm{mmol} / \mathrm{g} / \mathrm{h}$; both values were the highest among the tested strains. A high $\mathrm{q}_{\mathrm{Ac}}$ of $4.31 \mathrm{mmol} / \mathrm{g} / \mathrm{h}$ was determined and no other by-products were observed. The biomass yield from glucose $\left(\mathrm{Y}_{\mathrm{x} / \mathrm{s}}\right)$ was $52.44 \mathrm{~g} / \mathrm{mol}$, the lowest value observed among strains in this study. Strain VH33 displayed a $\mu$ of $0.45 \mathrm{~h}^{-1}$ and a specific glucose uptake rate $\left(\mathrm{q}_{\mathrm{Glc}}\right)$ of $6.9 \mathrm{mmol} / \mathrm{g} / \mathrm{h}$. The specific acetate production rate $\left(\mathrm{q}_{\mathrm{Ac}}\right)$ was $5 \%$ of the value observed in W3110. When compared to the wild type strain, the $\mathrm{Y}_{\mathrm{x} / \mathrm{s}}$ in VH33 increased 20\%. Deletion of $p y k A$ 


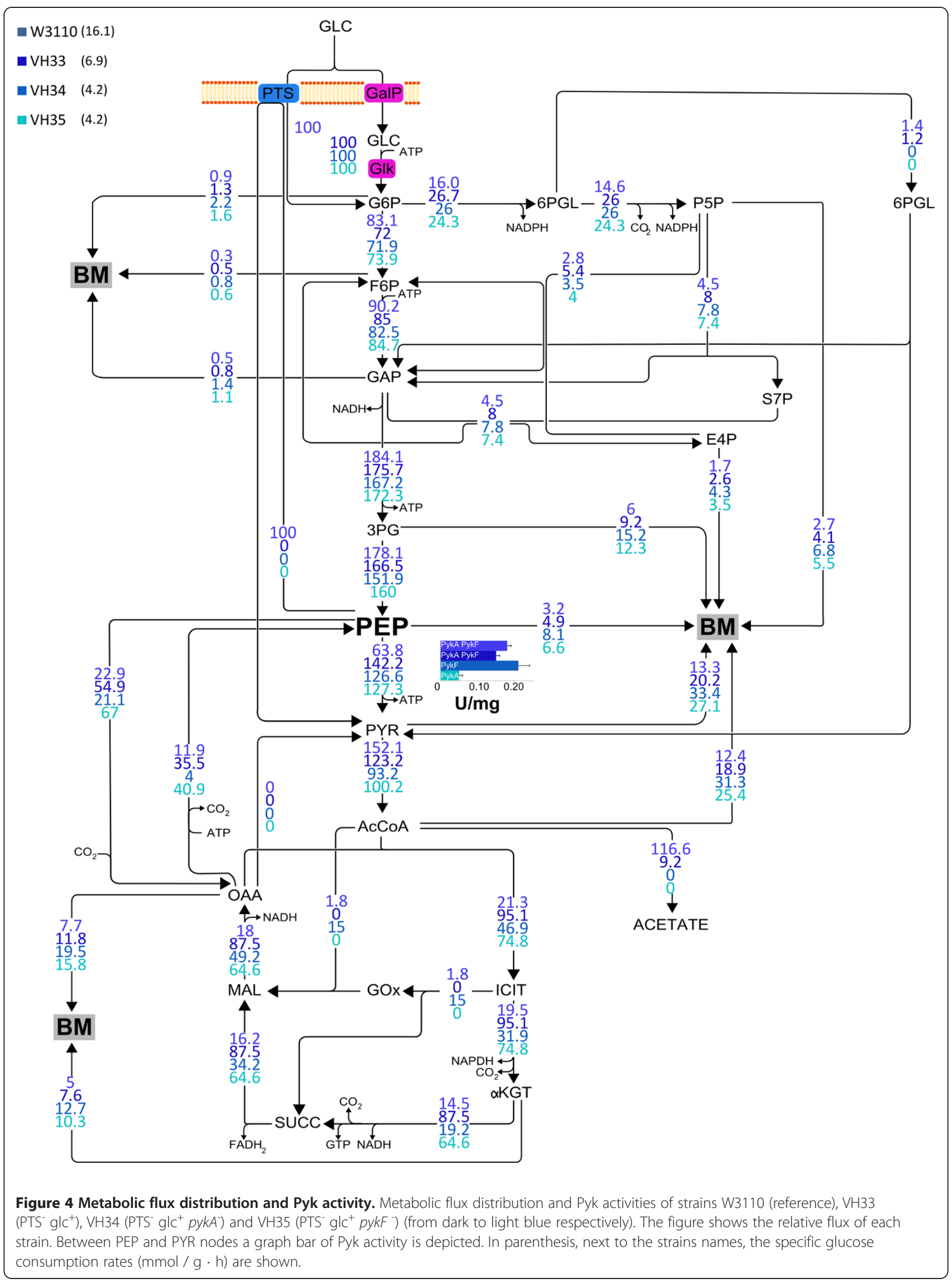


Table 2 Growth kinetic parameters in minimal media

\begin{tabular}{|c|c|c|c|c|c|}
\hline Strain & $\mu\left(h^{-1}\right)$ & $\mathrm{Y}_{\mathrm{x} / \mathrm{s}}(\mathrm{g} / \mathrm{mol})$ & $\mathrm{q}_{\mathrm{s}}(\mathrm{mmol} / \mathrm{g} / \mathrm{h})$ & $\mathrm{Y}_{\mathrm{Ac} / \mathrm{Glc}}(\mathrm{mol} / \mathrm{mol})$ & $q_{A c}(\mathrm{mmol} / \mathrm{g} / \mathrm{h})$ \\
\hline W3110 (WT) & $0.69 \pm 0.01$ & $52.44 \pm 4.42$ & $16.1 \pm 0.33$ & $1.2 \pm 0.01$ & $4.31 \pm 0.12$ \\
\hline VH33 (PTS') & $0.45 \pm 0.00$ & $63 \pm 3.60$ & $6.9 \pm 0.61$ & $0.09 \pm 0.00$ & $0.23 \pm 0.00$ \\
\hline VH34 (PTS' pykA) & $0.44 \pm 0.00$ & $104.4 \pm 16.20$ & $4.2 \pm 0.61$ & - & - \\
\hline VH35 (PTS' pykF-) & $0.36 \pm 0.01$ & $84.6 \pm 9.00$ & $4.2 \pm 0.41$ & - & - \\
\hline W3110 pck & $0.64 \pm 0.04$ & $51.76 \pm 1.93$ & $12.44 \pm 0.23$ & $0.32 \pm 0.03$ & $1.14 \pm 0.01$ \\
\hline VH33 pck' (PTS pck) & $0.37 \pm 0.00$ & $80.47 \pm 0.86$ & $4.61 \pm 0.09$ & $0.01 \pm 0.01$ & $0.03 \pm 0.00$ \\
\hline VH34 pck (PTS pykA- pck) & $0.33 \pm 0.02$ & $101.00 \pm 2.87$ & $3.35 \pm 0.13$ & - & - \\
\hline VH35 pck (PTS- pykF- pck') & $0.29 \pm 0.00$ & $73.32 \pm 2.06$ & $3.96 \pm 0.13$ & - & - \\
\hline
\end{tabular}

(VH34) had no significant effect on the $\mu\left(0.44 \mathrm{~h}^{-1}\right)$, whereas deletion of pykF (VH35) had a negative effect $\left(0.36 \mathrm{~h}^{-1}\right)$. Both strains showed the same qGlc value $(4.2 \mathrm{mmol} / \mathrm{g} / \mathrm{h})$ and no acetate production was detected. The highest $Y_{x / s}$ value among all tested strains was observed for strain VH34 (Table 2).

\section{Metabolic flux responses to PTS inactivation}

To determine in fine detail the consequences of PTS and PykA or PykF inactivation on central carbon metabolism, ${ }^{13} \mathrm{C}$ metabolic flux analysis was performed. In reference strain W3110, the EMP pathway was identified as the main metabolic route involved in glucose catabolism, the PPP had a minor role and the EntnerDuodoroff pathway (EDP) was hardly active. The TCA cycle displayed a low carbon flux value and the glyoxylate shunt was slightly active (Figure 4). It is noteworthy that a low level of carbon exchange was detected between PEP and OAA (catalyzed by Ppc and Pck), forming a cycle where one ATP molecule is hydrolyzed.

PTS inactivation had a strong effect on the metabolic flux distribution throughout the whole central metabolic network. The EMP pathway relative flux was reduced while PPP and TCA cycle fluxes were increased. When compared to data from strain W3110, an increase in the exchange rate between PEP and OAA, involving Ppc and Pck, was observed. Also, strain VH33 displayed higher carbon flux to biomass when compared to the wild-type strain. At the lower part of the EMP pathway, the total $\mathrm{PEP} \rightarrow$ PYR flux decreased from $163 \%$ in W3110 to $142 \%$ in VH33; however, the flux dependent only on Pyk isozymes activity increased from $63.8 \%$ in W3110 to $142.2 \%$ in the PTS $^{-}$glc $^{+}$strain. The flux from acetyl coenzyme A (AcCoA) to acetate was reduced from $116 \%$ in W3110 to 9\% in VH33. When compared to W3110, a 4 fold higher flux into the TCA was observed in strain VH33.

\section{Metabolic flux responses to Pyk isozyme inactivation in the PTS glc $^{+}$background.}

Inactivation of either Pyk isozyme in the PTS ${ }^{-}$glc $^{+}$background caused a similar level of reduction in $\mathrm{q}_{\mathrm{s}}$ and $\mathrm{q}_{\mathrm{ac}}$, and the magnitude of the flux from PEP to PYR was similar in both strains. However, values for $\mu, \mathrm{Yx} / \mathrm{s}$ and Pyk activity, differed between strains VH34 and VH35. Compared to strain VH34, the anaplerotic flux from PEP to OAA was 3 fold higher in VH35, and the flux directed to the TCA cycle via GltA was also higher (Figure 4). Flux from AcCoA to acetate was absent in both strains and the glyoxylate shunt was found to be active only in VH34. A high carbon exchange flux between PEP and OAA was found in VH35, whereas for VH34 the exchange flux value was the lowest of all studied strains. When compared to strain VH33, it was observed that inactivation of either Pyk isozyme caused an increase in carbon flux directed to biomass formation.

\section{Physiological responses to Pck inactivation}

The flux analysis data revealed the existence of a metabolic cycle involving Ppc and Pck in all studied strains. In order to gain more insight into the role of this cycle, we generated pck mutant derivatives of W3110, VH33, VH34 and VH35. When these derivative strains were cultured in minimal medium with glucose as sole carbon source, a reduction in $\mu$ and qs was observed. Also, a $75 \%$ and $87 \%$ reduction in the rate of acetate production was observed in strains W3110 and VH33, respectively (Table 2).

\section{Aromatic amino acids production}

The effects of PTS and Pyk inactivation on aromatics production capacity, was determined on strains W3110A, VH33A, VH34A and VH35A that carry plasmids pJLBaroG ${ }^{\mathrm{fbr}} t k t \mathrm{~A}$ and $\mathrm{p} \operatorname{Trcphe} A^{\mathrm{ev} 2}$ having genes encoding enzymes that increase carbon flow from central metabolism to the common aromatic and PHE biosynthetic pathways. These modifications cause an increase in PHE production capacity. However, accumulation and secretion of pathway intermediates such as DHS and SHIK also occurs as consequence of pathway bottlenecks in the common aromatic pathway.

Metabolites DHS and SHIK as well as PHE, were quantified from supernatants of resting cells cultures. Figure 2a and Table 3 show the calculated yields from glucose for DHS, SHIK and PHE, as well as the sum of 
Table 3 Batch profiles and common shikimate pathway intermediaries and phenylalanine yields from glucose of W3110A, VH33A, VH34A and VH35A resting cells in minimal media

\begin{tabular}{lcccccc}
\hline Strain & $\begin{array}{c}\mathbf{q}_{\mathbf{s}} \\
(\mathbf{m m o l} / \mathbf{g} / \mathbf{h})\end{array}$ & $\begin{array}{c}\mathbf{q}_{\mathrm{Ac}} \\
(\mathbf{m m o l} / \mathbf{g} / \mathbf{h})\end{array}$ & $\begin{array}{c}\mathbf{Y}_{\mathrm{DHS}} / \mathrm{Glc} \\
(\mathbf{m o l} / \mathbf{m o l})\end{array}$ & $\begin{array}{c}\mathbf{Y}_{\mathrm{SHIK}} / \mathrm{Glc} \\
(\mathbf{m o l} / \mathbf{m o l})\end{array}$ & $\begin{array}{c}\mathbf{Y}_{\mathrm{PHE}} / \mathrm{Glc} \\
(\mathbf{m o l} / \mathbf{m o l})\end{array}$ & $\begin{array}{c}\mathrm{Y}_{\mathrm{DHS}+S H I K+P H E} / \mathrm{Glc} \\
(\mathbf{m o l} / \mathbf{m o l})\end{array}$ \\
\hline W3110A & $2.51 \pm 0.10$ & $7.52 \pm 0.46$ & $0.01 \pm 0.00$ & $0.00 \pm 0.00$ & $0.04 \pm 0.01$ & $0.05 \pm 0.01$ \\
VH33A & $0.70 \pm 0.04$ & - & $0.13 \pm 0.03$ & $0.06 \pm 0.01$ & $0.25 \pm 0.03$ & $0.44 \pm 0.06$ \\
VH34A & $1.96 \pm 0.02$ & - & $0.05 \pm 0.01$ & $0.04 \pm 0.00$ & $0.08 \pm 0.00$ & $0.17 \pm 0.01$ \\
VH35A & $0.91 \pm 0.04$ & - & $0.24 \pm 0.01$ & $0.06 \pm 0.00$ & $0.03 \pm 0.01$ & $0.33 \pm 0.02$ \\
\hline
\end{tabular}

these three compounds $\left(\mathrm{Y}_{\mathrm{DHS}+\mathrm{SHIK}+\mathrm{PHE} / \mathrm{Glc}}\right)$. A yield value that includes the sum of the amounts detected for DHS, SHIK and PHE is the best indicator of aromatics production capacity, which itself is directly related to PEP biosynthetic availability. Inactivation of PTS caused a near 10-fold increase in $\mathrm{Y}_{\mathrm{DHS}+\mathrm{SHIK}+\mathrm{PHE} / \mathrm{Glc}}$ when compared to wild-type strain W3110. This is the result of replacing PEP-dependent glucose transport in the wildtype strain by an ATP-dependent mechanism in strain VH33 [23,30]. In the PTS ${ }^{-}$glc $^{+}$background, inactivation of PykA (VH34) or PykF (VH35) caused 3.4 and 6.6-fold increases in $\mathrm{Y}_{\mathrm{DHS}+\mathrm{SHIK}+\mathrm{PHE} / \mathrm{Glc}}$ when compared to W3110.

\section{Discussion}

The objective of the present work consisted on determining the effects of PTS and Pyk isozymes inactivation on cell physiology, metabolic flux distribution and PEP availability for aromatics biosynthesis. The inactivation of PTS in E. coli abolishes PEP-dependent glucose transport; therefore PYR production from PEP is dependent only on Pyk isozyme activities. In this study, by inactivating each Pyk isozyme in a PTS $^{-}$glc ${ }^{+}$background, strains were generated where the PEP to PYR reaction was dependent only on PykA or PykF activity. These strains were characterized by flux analysis, thus providing the first quantitative description of the metabolic consequences of the sequential elimination of activities catalyzing the PEP to PYR reaction.

The inactivation of PTS in E. coli causes a strong reduction in $\mathrm{q}_{\mathrm{Glc}}$ and $\mu$, therefore, such mutant strains display a PTS $^{-}$glc $^{-}$phenotype. To improve $\mathrm{q}_{\text {Glc }}$ and $\mu$, strain VH33 has a chromosomal modification that increases its capacity for non PTS-dependent glucose transport and thus displays a $\mathrm{PTS}^{-}$glc $^{+}$phenotype. In strain VH33 glucose phosphorylation is not dependent on PEP; instead, ATP is the phosphate donor in a reaction catalyzed by glucokinase. The $\mu$ of the $\mathrm{PTS}^{-}$glc $^{-}$ progenitor strain VH32 is $0.03 \mathrm{~h}^{-1}$, whereas this value increased to $0.45 \mathrm{~h}^{-1}$ in $\mathrm{VH} 33$ as a result of replacing the native promoter of gene galP with the strong promoter trc [50]. In this study, the qGlc of strain VH33 was determined and it corresponded to $43 \%$ of that measured in wild-type W3110. An expected consequence of the lower $\mathrm{q}_{\text {Glc }}$ in VH33 is a decreased flux in the EMP pathway. The flux analyses performed in this report revealed that the main observed response to PTS inactivation was flux rerouting at the $\mathrm{AcCoA}$ node, resulting in a highly reduced $\mathrm{q}_{\mathrm{Ac}}$. This metabolic response is expected to compensate for the reduced glycolytic flux in strain VH33, diverting the AcCoA not consumed for acetate production mainly into the TCA cycle. The net result is an augmented flux into the TCA cycle with an expected increase in the synthesis rate of biomass precursors $\alpha K G T$ and OAA, as well as reduced cofactors that can lead to ATP synthesis by oxidative phosphorylation. Inactivation of either PykA or PykF in the $\mathrm{PTS}^{-}$glc $^{+}$background caused an approximately further 50\% reduction in $\mathrm{q}_{\text {Glc }}$ and flux in the PEP to PYR reaction when compared to data from VH33. These results indicate that both isozymes should be active to sustain the high flux level in this part of the EMP pathway when E. coli grows on glucose. Acetate production was not detected in strains $\mathrm{VH} 34$ and $\mathrm{VH} 35$. In these strains, the relative flux to the TCA cycle was higher than that observed for W3110 but lower than the value for VH33. A second observed response to PTS or PTS and Pyk inactivation consisted in flux rerouting in the central metabolic network leading to increased flux to biomass generation. The flux value to biomass was nearly twofold higher in strains VH34 and VH35, when compared to VH33. This metabolic response can be expected to have the effect of conserving the reduced amount of intermediate metabolites resulting from the diminished glucose import and catabolism capacity in the PTS $^{-}$and Pyk mutant strains. As expected, the flux values leading from the central metabolic pathways to biomass formation showed a positive correlation with the observed $\mathrm{Y}_{\mathrm{x} / \mathrm{s}}$ in all studied strains.

Evidence of cycling via Ppc and Pck was detected in the wild-type strain W3110. This metabolic cycle has also been reported by other authors in wild-type $E$. coli $[26,27]$. A comparison among the mutant strains generated in this study provides the opportunity to explore the role of this cycle in E. coli. Flux analysis revealed that PTS inactivation causes an increase in the cycle net flux. A similar response is observed by simultaneous PTS and PykF inactivation (strain VH35). In contrast, the lowest net flux value was observed in strain VH34 that lacks 
PTS and PykA activities. These results suggest a partial inverse correlation between $\mathrm{q}_{\mathrm{s}}$ and the net flux in this metabolic cycle, which can be observed when comparing strains W3110, VH33 and VH35. It is not clear why this correlation does not apply for strain VH34. This might be related to the differential effects of PykA or PykF inactivation on the metabolic flux distribution around the PEP node. In a previous report, when comparing a wild-type strain and a derivative lacking both PykA and PykF activities, the Pyk double mutant displayed a higher cycle net flux [26]. However, in this case, the $\mathrm{q}_{\mathrm{Glc}}$ of the strains were similar, so the observed effect must be mainly related to the reduced flux in the PEP to PYR reaction.

The ATP/ADP ratio is an important physiologic parameter that modulates several cellular functions. It has been observed that a reduction in the ATP/ADP ratio, caused by increasing ATP hydrolysis activities, stimulates flux in the EMP pathway [58]. Each cycle involving Ppc and Pck activities consumes one ATP molecule. Thus, a reduction in the cellular ATP/ADP ratio could be expected at high Ppc-Pck cycle flux values, and this could stimulate EMP pathway flux. The observed inverse correlation between $\mathrm{q}_{\mathrm{Glc}}$ and the net cycle flux in strains W3110, VH33 and VH35 suggests this cycle might be contributing to increasing EMP pathway flux and thus, growth capacity in the mutant strains. To test this hypothesis, mutant derivatives of strains W3110, VH33, VH34 and VH35 lacking Pck activity were constructed and characterized. A reduction in $\mathrm{q}_{\mathrm{Glc}}$ and $\mu$ was observed in all derivative Pck strains, suggesting that the Ppc-Pck cycle's function is related to stimulating flux in the EMP pathway.

Some of the metabolic responses discussed above, that include $\mathrm{q}_{\text {Glc }}$ reduction and flux rerouting at several points in central metabolism can be partially explained considering that PEP has a role in the allosteric regulation of several enzymes of the EMP pathway. In addition, inhibition of glucokinase by PEP has been reported [9]. Considering the genetic modifications performed, a larger PEP pool would be expected in strains VH33, VH34 and VH35 when compared to W3110. This assumption is consistent with the higher metabolic PEP availability demonstrated in PTS $^{-}$glc $^{+}$strains that have been shown to produce aromatic compounds with a higher yield from glucose and with data from PTS- Pykmutats that will be discussed below [23,30].

Strains W3110A, VH33A, VH34A and VH35A carry plasmids with genes encoding enzymes that increase carbon flow into the common aromatic and the PHE biosynthetic pathways (Figure 2a and Table 3). When considering the $\mathrm{Y}_{\mathrm{DHS}+\mathrm{SHIK}+\mathrm{PHE} / \mathrm{Glc}}$ from resting cells experiments in minimal medium with glucose, it can be observed, as expected, that PTS inactivation causes an increase in this parameter. In the $\mathrm{PTS}^{-}$glc $^{+}$background, inactivation of PykA (VH34A) or PykF (VH35A), would be expected to further increase PEP availability for aromatics biosynthesis. However, the $\mathrm{Y}_{\mathrm{DHS}+\mathrm{SHIK}+\mathrm{PHE} / \mathrm{Glc}}$ value was lower in these two strains when compared to VH33A. These results can be explained considering that in strains VH34 and VH35 a higher flux value is directed from central metabolism to biomass formation when compared to VH33. In strains VH34 and VH35, an inverse correlation was observed between $\mathrm{Y}_{\mathrm{x} / \mathrm{Glc}}$ and $\mathrm{Y}_{\mathrm{DHS}}$ + SHIK+PHE/Glc. These data indicates that a carbonlimitation state in minimal medium with glucose reduces PEP availability for aromatics production in strains VH34 and VH35 as a result of competition for central metabolic precursors, including PEP, between biomass formation reactions and the modified aromatic pathways in stains VH34A and VH35A. Consumption of precursors for biomass synthesis from central metabolism could be reduced in these two strains if they are provided in the culture medium. When resting cells experiments were performed in minimal medium supplemented with yeast extract $(10 \mathrm{~g} / \mathrm{l})$, a 19,14 and 25 fold increase was observed in VH33A, VH34A and VH35A in $\mathrm{Y}_{\mathrm{DHS}+\mathrm{SHIK}+\mathrm{PHE} / \mathrm{Glc}}$ values when compared with W3110 (data not shown). In addition, two reports have shown that strains with $\mathrm{PTS}^{-}$glc $^{+} \mathrm{PykA}^{-}$or PTS glc $^{+}$PykF $F^{-}$phenotypes display higher production capacity for aromatic compounds in complex media when compared to an isogenic PTS ${ }^{-}$glc $^{+}$strain $[17,22]$.

It has been shown that a strain having the same phenotype as VH33 displays a better production performance for recombinant protein production when compared to W3110 [50]. This result can be explained by the lower $\mathrm{q}_{\mathrm{Ac}}$ and higher $\mathrm{Y}_{\mathrm{x} / \mathrm{Glc}}$ displayed by the $\mathrm{PTS}^{-}$glc $^{+}$mutant, when compared to the wild-type strain. In this regard, it is noteworthy that inactivation of either Pyk isozyme in VH33 caused a further reduction in $\mathrm{Y}_{\mathrm{Ac} / \mathrm{Glc}}$ to the point where this organic acid was not detected by HPLC. Interestingly, strain VH34 displayed no acetate production, a $66 \%$ increase in $\mathrm{Y}_{\mathrm{x} / \mathrm{s}}$ over $\mathrm{VH} 33$ and the same $\mu$. In a recent report, strain VH34 transformed with a plasmid DNA vaccine (pDNA) and grown in complex medium supplemented with glucose produced $50 \%$ less acetate and nearly 4-fold more pDNA when compared to strain VH33/pDNA [59]. These data shows that strain VH34 has advantageous characteristics for a microbial host that could be employed for the development of fermentative process for plasmid DNA or recombinant protein production.

\section{Conclusions}

In this study, the contribution of PTS and each of the Pyk isozymes to the PEP to PYR flux as well as the consequences of their inactivation on central metabolism were determined by metabolic flux analysis. This work showed that the presence of either one of the two Pyk isozymes generates quite different physiological and central carbon 
metabolism flux responses. The general observed response to PTS or Pyk inactivation is consistent with central metabolism flux rerouting to compensate for the lower EMP flux observed in these mutant strains. The detailed characterization presented here provides further insight into the flexibility of the central metabolic network in $E$. coli and will be useful in the design of strategies for generating strains for the production of aromatic metabolites, plasmid DNA or recombinant proteins.

\author{
Abbreviations \\ Metabolic pathways \\ EMP: Embden Meyerhof Parnas; TCA: Tricarboxylic acid cycle; PPP: Pentose \\ pathway. \\ Enzymes \\ GalP: Galactose permease; Gap: Glyceraldehydes 3-phosphate \\ dehydrogenase; Glk: Glucokinase; GltA: Citrate synthase; Gnd: \\ 6-phosphogluconate dehydrogenase; Mdh: Malate dehydrogenase; \\ Mez: NAD- and NADP dependent malic enzymes; Pck: Phosphoenolpyruvate \\ carboxykinase; Pgi: Phosphoglucose isomerase; Ppc: Phosphoenolpyruvate \\ carboxylase; PTS: Phosphoenolpyruvate:carbohydrate phosphotransferase \\ system; PykAF: Pyruvate kinases A and F; Zwf: Glucose 6-phosphate \\ dehydrogenase. \\ Compounds and others \\ AcCOA: Acetyl-coenzyme A; CIT: Citrate; E4P: Erythose 4-phosphate; \\ F6P: Fructose 6-phosphate; aKGT: a-ketoglutarate; GAP: Glyceraldehydes \\ 3-phosphate; G6P: Glucose 6-phosphate; Glc: Glucose; GOx: Glyoxylate shunt; \\ ICIT: Isocitrate; MAL: Malate; NADPH: Nicotinamide adenine dinucleotide \\ phosphate (reduced form); NADH: Nicotinamide adenine dinucleotide \\ (reduced form); OAA: Oxaloacetate; 2PG: 2-phosphoglycerate; \\ 3PG: Phosphoglycerate; 6PGL: 6-phosphogluconolactone; \\ PEP: Phosphoenolpyruvate; PYR: Pyruvate; R5P: Ribose 5-phosphate; \\ SUCC: Succinate; BM: Biomass.
}

\section{Competing interests}

The authors declare that they have no competing interests.

\section{Authors' contributions}

$E M, F B, G G$ and $C W$ participated in the design of this study. EM constructed the strains, realized the batch cultures and performed Pyk activity and HPLC determinations. JB designed the $1-{ }^{13} \mathrm{C}$ glucose labeled experiments, the derivatization and GC-MS analysis of the hydrolizates. JB and CW did the modeling of the network for relative flux determination. $\mathrm{EM}, \mathrm{JB}, \mathrm{FB}, \mathrm{GG}$ and CW participated in the analysis of the results as well as in writing and critical review of the manuscript. All authors have read and approved the manuscript.

\section{Acknowledgements}

This work was supported by CONACyT grants 83039 and 126793. EM was supported by a fellowship from CONACyT. We thank Georgina HernandezChavez and Mercedes Enzaldo for technical assistance.

\section{Author details}

${ }^{1}$ Cellular Engineering and Biocatalysis Department, Biotechnology Institute, Universidad Nacional Autónoma de México, Apdo. Postal 510-3, Cuernavaca Morelos 62210, Mexico. ${ }^{2}$ Institute of Biochemical Engineering, Technische Universität Braunschweig, Gaußstr. 17, D-38106, Braunschweig, Germany.

Received: 23 July 2012 Accepted: 6 September 2012 Published: 13 September 2012

\section{References}

1. Fraenkel DG: Glycolysis, pentose phosphate pathway, and Entner-Duodoroff pathway. In Escherichia coli and Salmonella typhimurium. Washington DC: American Society for Microbiology; 1987.

2. Deutscher J, Francke C, Postma PW: How phosphotransferase system-related protein phosphorylation regulates carbohydrate metabolism in bacteria. Microbiol Mol Biol Rev 2006, 70:939-1031.
3. Lang VJ, Leystra-Lantz C, Cook RA: Characterization of the specific pyruvate transport system in Escherichia coli K-12. J Bacteriol 1987, 169:380-385.

4. Postma PW, Lengeler JW, Jacobson GR: Phosphoenolpyruvate: carbohydrate phosphotransferase systems of bacteria. Microbiol Rev 1993, 57:543-594.

5. Munoz ME, Ponce E: Pyruvate kinase: current status of regulatory and functional properties. Comp Biochem Physiol B Biochem Mol Biol 2003, 135:197-218.

6. Morikawa M, Izui K, Taguchi M, Katsuki H: Regulation of Escherichia coli phosphoenolpyruvate carboxylase by multiple effectors in vivo. Estimation of the activities in the cells grown on various compounds. J Biochem 1980, 87:441-449.

7. Sauer U, Eikmanns BJ: The PEP-pyruvate-oxaloacetate node as the switch point for carbon flux distribution in bacteria. FEMS Microbiol Rev 2005, 29:765-794.

8. Chao YP, Patnaik R, Roof WD, Young RF, Liao JC: Control of gluconeogenic growth by pps and pck in Escherichia coli. J Bacteriol 1993, 175:6939-6944.

9. Ogawa T, Mori H, Tomita M, Yoshino M: Inhibitory effect of phosphoenolpyruvate on glycolytic enzymes in Escherichia coli. Res Microbiol 2007, 158:159-163.

10. Campos-Bermudez VA, Bologna FP, Andreo CS, Drincovich MF: Functional dissection of Escherichia coli phosphotransacetylase structural domains and analysis of key compounds involved in activity regulation. FEBS $J$ 2010, 277:1957-1966.

11. Jensen RA, Nasser DS: Comparative regulation of isoenzymic 3-deoxy-Darabino-heptulosonate 7-phosphate synthetases in microorganisms. J Bacteriol 1968, 95:188-196.

12. Bondinell WE, Vnek J, Knowles PF, Sprecher M, Sprinson DB: On the mechanism of 5-enolpyruvylshikimate 3-phosphate synthetase. J Biol Chem 1971, 246:6191-6196.

13. Sprenger GA: From scratch to value: engineering Escherichia coli wild type cells to the production of L-phenylalanine and other fine chemicals derived from chorismate. Appl Microbiol Biotechnol 2007, 75:739-749.

14. Chotani G, Dodge T, Hsu A, Kumar M, LaDuca R, Trimbur D, Weyler W, Sanford K: The commercial production of chemicals using pathway engineering. Biochim Biophys Acta 2000, 1543:434-455.

15. Gosset G: Improvement of Escherichia coli production strains by modification of the phosphoenolpyruvate:sugar phosphotransferase system. Microb Cell Fact 2005, 4:14.

16. Gosset G: Production of aromatic compounds in bacteria. Curr Opin Biotechnol 2009, 20:651-658.

17. Gosset G, Yong-Xiao J, Berry A: A direct comparison of approaches for increasing carbon flow to aromatic biosynthesis in Escherichia coli. J Ind Microbiol 1996, 17:47-52

18. Leuchtenberger W, Huthmacher K, Drauz K: Biotechnological production of amino acids and derivatives: current status and prospects. Appl Microbiol Biotechnol 2005, 69:1-8.

19. Yi J, Draths KM, Li K, Frost JW: Altered glucose transport and shikimate pathway product yields in E. coli. Biotechnol Prog 2003, 19:1450-1459.

20. Munoz AJ, Hernandez-Chavez G, de Anda R, Martinez A, Bolivar F, Gosset G: Metabolic engineering of Escherichia coli for improving L: -3,4dihydroxyphenylalanine (L: -DOPA) synthesis from glucose. J Ind Microbiol Biotechnol 2011, 19:1845-1852.

21. Dewick PM (Ed): Medicinal natural products: A biosynthetic Approach. 3rd edition. Great Britain: Antony Rowe Ltd; 2009.

22. Escalante A, Calderon R, Valdivia A, de Anda R, Hernandez G, Ramirez OT, Gosset G, Bolivar F: Metabolic engineering for the production of shikimic acid in an evolved Escherichia coli strain lacking the phosphoenolpyruvate: carbohydrate phosphotransferase system. Microb Cell Fact 2010, 9:21.

23. Baez JL, Bolivar F, Gosset G: Determination of 3-deoxy-D-arabinoheptulosonate 7-phosphate productivity and yield from glucose in Escherichia coli devoid of the glucose phosphotransferase transport system. Biotechnol Bioeng 2001, 73:530-535.

24. Patnaik R, Liao JC: Engineering of Escherichia coli central metabolism for aromatic metabolite production with near theoretical yield. Appl Environ Microbiol 1994, 60:3903-3908.

25. Al Zaid Siddiquee K, Arauzo-Bravo MJ, Shimizu K: Metabolic flux analysis of pykF gene knockout Escherichia coli based on 13C-labeling experiments 
together with measurements of enzyme activities and intracellular metabolite concentrations. Appl Microbiol Biotechnol 2004, 63:407-417.

26. Emmerling $M$, Dauner $M$, Ponti A, Fiaux J, Hochuli M, Szyperski T, Wuthrich K, Bailey JE, Sauer U: Metabolic flux responses to pyruvate kinase knockout in Escherichia coli. J Bacteriol 2002, 184:152-164.

27. Flores S, Gosset G, Flores N, de Graaf AA, Bolivar F: Analysis of carbon metabolism in Escherichia coli strains with an inactive phosphotransferase system by (13)C labeling and NMR spectroscopy. Metab Eng 2002, 4:124-137.

28. Ponce E, Flores N, Martinez A, Valle F, Bolivar F: Cloning of the two pyruvate kinase isoenzyme structural genes from Escherichia coli: the relative roles of these enzymes in pyruvate biosynthesis. J Bacterio/ 1995, 177:5719-5722.

29. Siddiquee KA, Arauzo-Bravo MJ, Shimizu K: Effect of a pyruvate kinase (pykF-gene) knockout mutation on the control of gene expression and metabolic fluxes in Escherichia coli. FEMS Microbiol Lett 2004, 235:25-33.

30. Flores N, Xiao J, Berry A, Bolivar F, Valle F: Pathway engineering for the production of aromatic compounds in Escherichia coli. Nat Biotechnol 1996, 14:620-623.

31. Parker C, Barnell WO, Snoep JL, Ingram LO, Conway T: Characterization of the Zymomonas mobilis glucose facilitator gene product ( $g / f)$ in recombinant Escherichia coli: examination of transport mechanism, kinetics and the role of glucokinase in glucose transport. Mol Microbiol 1995, 15:795-802.

32. Baez-Viveros JL, Osuna J, Hernandez-Chavez G, Soberon X, Bolivar F, Gosset $\mathrm{G}$ : Metabolic engineering and protein directed evolution increase the yield of L-phenylalanine synthesized from glucose in Escherichia coli. Biotechnol Bioeng 2004, 87:516-524.

33. Malcovati M, Kornberg HL: Two types of pyruvate kinase in Escherichia coli K12. Biochim Biophys Acta 1969, 178:420-423.

34. Saeki T, Hori M, Umezawa H: Pyruvate kinase of Escherichia coli. Its role in supplying nucleoside triphosphates in cells under anaerobic conditions. J Biochem 1974, 76:631-637.

35. Valentini G, Stoppini M, ladarola P, Malcovati M, Ferri G, Speranza ML: Divergent binding sites in pyruvate kinases I and II from Escherichia coli. Biol Chem Hoppe Seyler 1993, 374:69-74

36. Bledig SA, Ramseier TM, Saier MH Jr: Frur mediates catabolite activation of pyruvate kinase (pykF) gene expression in Escherichia coli. J Bacteriol 1996, 178:280-283.

37. Saier MH Jr, Ramseier TM: The catabolite repressor/activator (Cra) protein of enteric bacteria. J Bacteriol 1996, 178:3411-3417.

38. Shimada T, Yamamoto K, Ishihama A: Novel members of the Cra regulon involved in carbon metabolism in Escherichia coli. J Bacteriol 2011 193:649-659.

39. Boiteux A, Markus M, Plesser T, Hess B, Malcovati M: Analysis of progress curves. Interaction of pyruvate kinase from Escherichia coli with fructose 1,6-bisphosphate and calcium ions. Biochem J 1983, 211:631-640.

40. Boyer PD: The inhibition of pyruvate kinase by ATP: a Mg++ buffer system for use in enzyme studies. Biochem Biophys Res Commun 1969, 34:702-706

41. Holmsen H, Storm E: The adenosine triphosphate inhibition of the pyruvate kinase reaction and its dependence on the total magnesium ion concentration. Biochem J 1969, 112:303-316.

42. Mattevi A, Bolognesi M, Valentini G: The allosteric regulation of pyruvate kinase. FEBS Lett 1996, 389:15-19.

43. Valentini G, Chiarelli L, Fortin R, Speranza ML, Galizzi A, Mattevi A: The allosteric regulation of pyruvate kinase. J Biol Chem 2000, 275:18145-18152.

44. Waygood EB, Mort JS, Sanwal BD: The control of pyruvate kinase of Escherichia coli. Binding of substrate and allosteric effectors to the enzyme activated by fructose 1,6-bisphosphate. Biochemistry 1976, 15:277-282.

45. Mort JS, Sanwal BD: The control of pyruvate kinases of Escherichia coli: further studies of the enzyme activated by ribose-5-phosphate. Can J Biochem 1978, 56:647-653.

46. Waygood EB, Rayman MK, Sanwal BD: The control of pyruvate kinases of Escherichia coli. II. Effectors and regulatory properties of the enzyme activated by ribose 5-phosphate. Can J Biochem 1975, 53:444-454.

47. Kohlstedt M, Becker J, Wittmann C: Metabolic fluxes and beyond-systems biology understanding and engineering of microbial metabolism. Appl Microbiol Biotechnol 2010, 88:1065-1075.
48. Bachmann BJ: Pedigrees of some mutant strains of Escherichia coli K-12. Bacteriol Rev 1972, 36:525-557.

49. Hernandez-Montalvo V, Martinez A, Hernandez-Chavez G, Bolivar F, Valle F, Gosset G: Expression of galP and glk in a Escherichia coli PTS mutant restores glucose transport and increases glycolytic flux to fermentation products. Biotechnol Bioeng 2003, 83:687-694.

50. De Anda R, Lara AR, Hernandez V, Hernandez-Montalvo V, Gosset G, Bolivar F, Ramirez OT: Replacement of the glucose phosphotransferase transport system by galactose permease reduces acetate accumulation and improves process performance of Escherichia coli for recombinant protein production without impairment of growth rate. Metab Eng 2006, 8:281-290.

51. Datsenko KA, Wanner BL: One-step inactivation of chromosomal genes in Escherichia coli K-12 using PCR products. Proc Natl Acad Sci U S A 2000 97:6640-6645

52. Cherepanov PP, Wackernagel W: Gene disruption in Escherichia coli: TcR and $\mathrm{KmR}$ cassettes with the option of Flp-catalyzed excision of the antibiotic-resistance determinant. Gene 1995, 158:9-14.

53. Sigala JC, Flores S, Flores N, Aguilar C, de Anda R, Gosset G, Bolivar F: Acetate metabolism in Escherichia coli strains lacking phosphoenolpyruvate: carbohydrate phosphotransferase system; evidence of carbon recycling strategies and cycles. J Mol Microbiol Biotechnol 2009, 16:224-235.

54. Oh MK, Rohlin L, Kao KC, Liao JC: Global expression profiling of acetategrown Escherichia coli. J Biol Chem 2002, 277:13175-13183.

55. Balderas-Hernandez VE, Sabido-Ramos A, Silva P, Cabrera-Valladares N Hernandez-Chavez G, Baez-Viveros JL, Martinez A, Bolivar F, Gosset G: Metabolic engineering for improving anthranilate synthesis from glucose in Escherichia coli. Microb Cell Fact 2009, 8:19.

56. Kiefer $P$, Heinzle $E$, Zelder $O$, Wittmann C: Comparative metabolic flux analysis of lysine-producing Corynebacterium glutamicum cultured on glucose or fructose. Appl Environ Microbiol 2004, 70:229-239.

57. Maitra PK, Lobo Z: A kinetic study study of glycolytic enzyme synthesis in yeast. J Biol Chem 1971, 246:13

58. Koebmann BJ, Westerhoff HV, Snoep JL, Nilsson D, Jensen PR: The glycolytic flux in Escherichia coli is controlled by the demand for ATP. J Bacteriol 2002, 184:3909-3916.

59. Pablos TE, Soto R, Mora EM, Le Borgne S, Ramirez OT, Gosset G, Lara AR: Enhanced production of plasmid DNA by engineered Escherichia coli strains. J Biotechnol 2011, 158(4):211-214.

doi:10.1186/1475-2859-11-127

Cite this article as: Meza et al:: Consequences of phosphoenolpyruvate: sugar phosphotranferase system and pyruvate kinase isozymes inactivation in central carbon metabolism flux distribution in Escherichia coli. Microbial Cell Factories 2012 11:127.

\section{Submit your next manuscript to BioMed Central and take full advantage of:}

- Convenient online submission

- Thorough peer review

- No space constraints or color figure charges

- Immediate publication on acceptance

- Inclusion in PubMed, CAS, Scopus and Google Scholar

- Research which is freely available for redistribution 